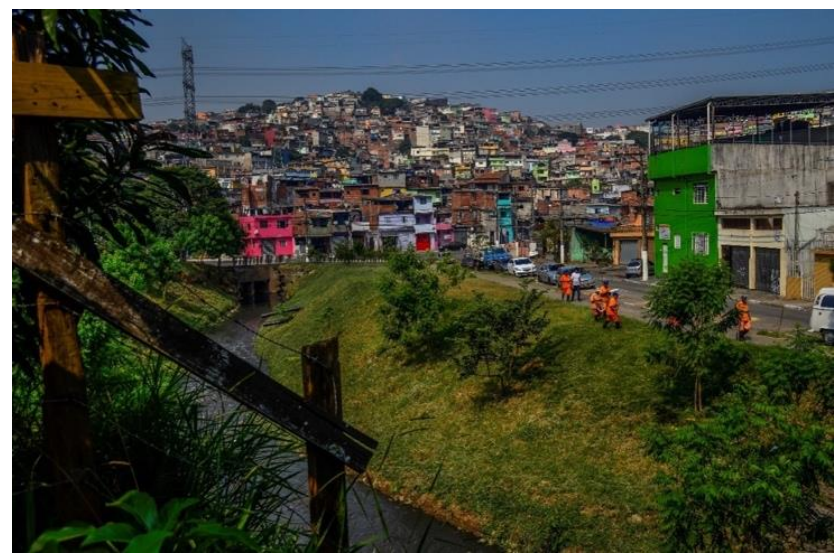

\title{
O direito ao (in) compressível: arte, cidade, paisagem e transformação social
}

\section{The right to (in) compressible: art, city, landscape and social transformation}

\author{
Catharina P. C. S. Lima ${ }^{1}$ \\ Elaine M. de Albuquerque ${ }^{2}$ \\ Gabriel C. dos Santos Lima ${ }^{3}$ \\ Hulda Erna Wehmann ${ }^{4}$
}

\section{Resumo:}

O presente artigo busca oferecer uma contribuição ao debate sobre o direito à cidade, partindo de discussões atuais no âmbito dos direitos humanos (demandas por lazer e à arte em paisagens qualificadas). Nesse sentido, partir-se-á de um texto de Antonio Candido de 1988, intitulado "O direito à literatura", a fim de agregar à discussão sobre a necessidade da arte outras dimensões, tais como o direito à paisagem, nas chaves de leitura crítica de mundo e instância qualificadora do cotidiano urbano. Com isso, propõe-se uma reflexão acerca do caráter incompressível de bens muitas vezes tomados pela sociedade como secundários ou supérfluos, sugerindo novas abordagens para as políticas urbanas.

Palavras-chave: Direito à cidade. Direito à paisagem. Direito à literatura.

\section{Abstract:}

The current article aims to offer a contribution to the debate on the right to the city, starting from nowadays discussions on human rights (demands for leisure and art in qualified landscapes). In this sense, it will take as a starting point a text by Antonio Candido from 1988, titled "O direito à literatura", in order to add other dimensions to the discussion about the necessity of art, such as the right to the landscape, in the keys of a critical reading of the world and qualifying instances of urban everyday life. Thus, we propose a reflection on the incompressible character of goods often taken by society as secondary or superfluous, suggesting new approaches to urban policies.

Keywords: Right to the City. Right to Landscape. Right to Literature.

\footnotetext{
${ }^{1}$ Arquiteta e Urbanista pela Universidade Federal do Rio Grande do Norte. Mestre e Doutora em Arquitetura e Urbanismo pela da Faculdade de Arquitetura e Urbanismo da Universidade de São Paulo. Professora doutora, do Departamento de Projeto da mesma instituição. Coordenadora do LABPARCLaboratório Paisagem Arte e Cultura. Editora - chefe da Revista Paisagem e Ambiente. Rua Antonio Aggio, n. 385, ap. 71, CEP 05713-420, Vila Andrade, São Paulo - SP. E-mail: cathypinheiro@ gmail.com ${ }^{2}$ Arquiteta e Urbanista graduada pela Universidade Braz Cubas, mestre e doutoranda em Arquitetura e Urbanismo pela Faculdade de Arquitetura e Urbanismo da Universidade de São Paulo. Rua Agulhas Negras, n. 391, CEP 09175-000, Vila Linda, Santo André - SP. E-mail: a3-arq@ uol.com.br ${ }^{3}$ Bacharel em Letras pela Faculdade de Filosofia, Letras e Ciências Humanas da Universidade de São Paulo, Mestre e Doutorando em Teoria Literária e Literatura Comparada e membro do Laboratório de Estudos do Romance da mesma Universidade. Rua Antonio Aggio, n. 385, ap. 71, CEP 05713-120, Vila Andrade, São Paulo - SP. E-mail: gabriel.cordeiro.lima@ usp.br

${ }^{4}$ Arquiteta e Urbanista graduada pela Universidade Federal do Ceará, Mestre em Ciências Regionais e Planejamento Espacial pelo Karlsruher Institut of Technology, Doutoranda em Arquitetura e Urbanismo pela Faculdade de Arquitetura e Urbanismo da Universidade de São Paulo. Professora da Escola de Ciências Exatas, Arquitetura e Design da Universidade Anhembi Morumbi. Rua Cônego Eugênio Leite, n. 892, ap. 96, CEP 05414-900, Pinheiros, São Paulo - SP. wehmann.hulda @ gmail.com
} 


\section{O direito à cidade: reivindicação do urbano como direito humano}

É possível dizer que a reivindicação do direito à cidade, bem como a reivindicação dos direitos humanos como um todo, se encontra hoje na ordem do dia se não dos governos, certamente dos movimentos sociais. Desde 2013, em função da onda de manifestações deflagrada pelo Movimento Passe Livre, a questão do transporte adquiriu maior visibilidade na agenda pública. No mesmo sentido, no Brasil do século XXI, novas formas de organização surgem com destaque no âmbito do enfrentamento político, levantando bandeiras pontuais ligadas ao urbano. São os casos, entre outros, do Movimento Parque Augusta em São Paulo ou o Ocupe Estelita em Recife, que se guiam pela defesa do interesse público em relação a áreas específicas na mira da especulação imobiliária. Isso para não falar em coletivos mais consolidados - em maior ou menor medida ligados à questão da cidade - como o Movimento dos Trabalhadores sem Teto (MTST) que protagoniza a luta popular por moradia e o Movimento Mães de Maio que combate a violência policial enfatizando o problema nas regiões periféricas.

Como se sabe, tais movimentos não centram fogo diretamente na questão dos meios de produção - razão pela qual sua relação com a esquerda tradicional nem sempre é das mais simples. Por outro lado, em torno de algumas de suas pautas giraram muitas das mais relevantes convulsões políticas e sociais recentes. Recorde-se, a título de exemplo, que no mesmo ano em que a tarifa de ônibus brasileira serviu como estopim para as jornadas de Junho, uma revolta popular na Turquia parou o país após repressão a uma manifestação inicialmente pacífica contra a demolição do parque Taksim Gezi.

O que todos esses processos têm em comum, a despeito de suas inúmeras diferenças, é uma ligação, em última instância, à questão fundamental dos direitos humanos (mais do que à própria questão da cidade). Todas as demandas que hoje fazem surgir coletivos e lutas localizadas - o direito ao transporte, o direito à moradia, o direito ao lazer, o direito à vida - podem ser perfeitamente entendidas sob esse arco. Por outro lado, suas consequências muitas vezes de amplo alcance nem sempre param por aí, se dirigindo muitas vezes a âmbitos ulteriores, como a administração pública, a desigualdade social e assim por diante. Quando esse processo não se esgota em si mesmo ou é intencionalmente direcionado para fins escusos, seus potenciais são gigantes. Por isso, algumas questões se impõem atualmente àqueles que se interessam pelos direitos humanos; a saber: qual é o potencial emancipatório da luta por cidades 
mais humanas? Como ela se liga a outros direitos? É possível que tantos movimentos já existentes encontrem uma chave reivindicatória para além do clientelismo estatal?

\section{Arte, tempo livre e outros (in) dispensáveis}

Gostaríamos de propor uma reflexão que, caso não possa resolver essas perguntas diretamente, pode ao menos sugerir tópicos a serem considerados em um processo mais geral de formulação de respostas. Nesse sentido, partiremos de um exemplo aparentemente inusitado: o da literatura. Sobretudo, tomaremos por base inicial o texto $O$ direito à literatura de Antonio Candido, de 1988. Não se trata, porém, de buscar correspondências conceituais entre uma ideia de literatura e uma ideia de cidade, de urbano. Antes, pensamos ser necessário compreender as lutas por esses bens (e outros mais) em suas semelhanças e possibilidades. Isso porque, no âmbito das políticas públicas, o texto de Candido apresenta postulados que ainda parecem inexplorados.

Em primeiro lugar, seu contexto é importante: trata-se do ano de redação da chamada Constituição Cidadã de 1988 - a despeito de suas inúmeras contradições, um momento ímpar na História do Brasil em termos da discussão sobre os rumos do país. Naquela ocasião, pressionadas que estavam pela sociedade civil organizada e pelo movimento mais geral da redemocratização, as instituições brasileiras se abriam a um debate amplo sobre leis trabalhistas, reforma agrária, tributária, urbana, entre outros temas que até hoje jazem esquecidos quando não trazidos à baila apenas para serem revisados no sentido mais regressivo. Da luta política em torno da Constituição, então, tomavam parte intelectuais que discutiam com o conjunto da população suas propostas.

O direito à literatura se destaca nesse panorama, por representar um libelo a um bem aparentemente muito supérfluo: a arte escrita. Não se trata, contudo, de inocência: nele, Candido demonstra total ciência da diferença entre os graus de importância da arte (um dia entendida por Ernest Fischer como uma "necessidade" (1977)) e, por exemplo, a comida - o mais indispensável dos bens. Aqui, o autor elabora uma distinção conceitual fundamental à reflexão sobre direitos humanos: a diferença entre bens “compressíveis" e "incompressíveis” (2007, p. 26). Diz Candido:

Certos bens são obviamente incompressíveis, como o alimento, a casa, a roupa. Outros são compressíveis, como os cosméticos, os enfeites, as roupas supérfluas. Mas a fronteira entre ambos é muitas vezes difícil de fixar, mesmo quando pensamos nos que são considerados indispensáveis. (...) O fato é que cada época e cada cultura fixam os 
critérios de incompressibilidade, que estão ligados à divisão da sociedade em classes, pois inclusive a educação pode ser instrumento para convencer as pessoas de que o que é indispensável para uma camada social não o é para outra (2007, p. 26).

O que nossa cultura, então, entende como incompressível? Ou melhor: o que ela deveria entender como incompressível? Não parece haver absolutamente nenhum dissenso no que tange a compressibilidade dos cosméticos - o próprio substantivo se transformou em adjetivo, sendo costumeiramente associado ao dispensável. Já a literatura, como percebeu Candido, é um caso mais complexo. Antes de tudo, o acesso à mesma requer instrução. Logo, em um país com índices de analfabetismo alarmantes, a produção literária enquanto demanda se vincula à mais urgente das necessidades. Em outro texto - Literatura e subdesenvolvimento, este de 1971 - Candido entendeu, inclusive, a difusão da literatura como um meio de resistência nacional ao imperialismo, ligada que estava a outras necessidades e consequências. Disse ele:

Se pensarmos nas condições materiais de existência da literatura, o fato básico talvez seja o analfabetismo, que nos países de cultura précolombiana adiantada é agravado pela pluralidade linguística ainda vigente, com as diversas línguas solicitando o seu lugar ao sol. Com efeito, ligam-se ao analfabetismo as manifestações de debilidade cultural: falta de meios de comunicação e difusão (editoras, bibliotecas, revistas, jornais); inexistência, dispersão e fraqueza dos públicos disponíveis para a literatura, devido ao pequeno número de leitores reais (muito menor que o número já reduzido de alfabetizados); impossibilidade de especialização dos escritores em suas tarefas literárias, geralmente realizadas como tarefas marginais ou mesmo amadorísticas; falta de resistência ou discriminação em face de influências e pressões externas. O quadro dessa debilidade se completa por fatores de ordem econômica e política, como os níveis insuficientes de remuneração e a anarquia financeira dos governos, articulados com políticas educacionais ineptas ou criminosamente desinteressadas. Salvo no tocante aos três países meridionais que formam a "América Branca" (no dizer dos europeus), tem sido preciso fazer revoluções para alterar as condições de analfabetismo predominante, como foi o caso lento e incompleto do México e o caso rápido de Cuba. (2011, p. 172 - 173)

Em outras palavras, para o intelectual, a literatura significava alfabetização e educação como condições prévias, pelas quais se faria necessária uma luta encarniçada nas esferas política e econômica. Algo, sem dúvida, muito diferente da concepção pedagógico-pacificadora que, na Inglaterra oitocentista, encontrou um expoente na figura de Matthew Arnold, autor de Culture and Anarchy (reedição vitoriana do 
binômio "civilização" e "barbárie"), cuja consigna pôde ser satirizada por Terry Eagleton como: "If the masses are not thrown a few novels, they may react by throwing up a few barricades" (1996, p. 26-27).

Se aceitamos a ideia de Candido, concluímos que, em última análise, a reivindicação do literário se ligaria a reivindicações mais amplas, cujo zenit seria a autonomia nacional. Certamente se crê possível prescindir da poesia, mas dificilmente se diria o mesmo da educação e da cultura. Entender a produção escrita nesse último marco mais geral qualificaria o debate em termos efetivamente emancipatórios. Esse salto do "compressível" a reivindicações mais amplas e universalistas parece dizer algo sobre os tempos atuais, em que os desdobramentos da substituição de um parque por um shopping acabam por desestabilizar um governo (como no já mencionado caso da Turquia).

Contudo, cabe ressaltar que o direito ao literário, como outros direitos, não deve se restringir jamais a uma mera possibilidade estratégica ou instrumental. Ainda segundo Candido, o fruir da ficção representa a possibilidade de se humanizar, aprofundando a experiência individual dentro de um circuito coletivo do qual a arte é, ela própria, um produto. Entre os estudiosos da teoria literária, tornou-se conhecida a frase: "a literatura não corrompe nem edifica (...) mas, trazendo livremente em si o que chamamos o bem e o que chamamos o mal, humaniza em sentido profundo, porque faz viver" (2011, p. 30).

Daí seguimos ao terceiro benefício inalienável da literatura para Candido: seu caráter de matéria mental formalmente organizada, sua capacidade de amoldar a experiência difusa em um todo autônomo, representando certo grau de organização mental do qual o ser humano jamais pode prescindir. Em outros termos, ler significaria organizar a mente, também dada a imprescindibilidade do sonhar, intrínseca à incapacidade de se manter desperto vinte e quatro horas por dia. $\mathrm{O}$ direito ao literário seria, assim, tanto o direito ao devaneio quanto à organização mental - uma importância, se se pode dizer, de dimensão cognitiva e psicológica.

Em que pese o caráter abstrato de tal definição, lembramos os contornos contrahegemônicos que o relaxamento espontâneo da mente assume em uma sociedade (como a nossa) marcada pela proliferação de neuroses de toda a sorte, produtos da exaustão psíquica desencadeada pela otimização do tempo em um contexto de exploração total. É preciso, portanto, entender a necessidade inalienável do tempo livre que, à altura da redemocratização de 1988, quando $O$ direito à literatura foi escrito, inseria-se 
concretamente em uma luta pela redução da jornada de trabalho- uma reivindicação sindical histórica - e hoje assume contornos dramáticos e potencialmente explosivos em face dos dados neoliberais.

Um diálogo possível: em 2007, o mesmo Antonio Candido já parecia pressentir algumas das enfermidades hoje epidêmicas que a monetarização do tempo desencadearia no século XXI. Dizia ele:

Chega a ser sinistro o famoso aforismo atribuído a Benjamin Franklin, um dos pais da independência estadunidense: ‘Tempo é dinheiro'. Isso é monstruoso, porque na verdade o tempo é o tecido da nossa vida, uma coisa preciosa, mesmo porque nos transforma a cada minuto, sendo certo que daqui a meia hora nós aqui presentes não seremos os mesmos. Portanto, é preciso prever formas mais altas de ocupação do tempo (CANDIDO, 2007, p. 66).

Hoje, as tendências modernas ali associadas a Benjamin Franklin parecem se radicalizar já que, como observou Byung-Chul Han, "No empuxo daquela positivação geral do mundo, tanto o homem quanto a sociedade se transformam numa máquina de desempenho autista" (2007, p. 56). Nessa era de concorrência estimulada, de ganho por hora de trabalho, de avaliações de desempenho e de novas formas de autoempreendimento (como o Uber ou as diversas representações comerciais), o direito ao tempo livre surge na contramão de um mundo automatizado.

O que estamos postulando é que, conforme formulado por um de seus principais teóricos, a literatura - aparentemente um bem muito supérfluo, inútil - já foi entendida como um bem incompressível, cuja reivindicação apontava para transformações sociais amplas e concretas, pois as pressupunha. $\mathrm{Na}$ atual "Sociedade do cansaço" (HAN, 2007), esse tipo de bem - justamente por seu caráter “inútil”, ligado ao tempo nãoprodutivo - apresenta um papel social ainda mais significativo.

Algumas demandas que atualmente surgem das ruas de forma espontânea e autoorganizada (portanto não são nem concebidas pela intelligentsia oficial nem impostas de cima para baixo por instituições) frequentemente são, em sentido contrário, enxergadas como bens "compressíveis". Este parece ser o caso de muitas pautas relacionadas ao 
urbano, como o direito ao lazer, ao parque público ou (gostaríamos de acrescentar) à paisagem. O que as ruas têm a dizer sobre nosso tempo? É possível inserir suas reivindicações em uma agenda mais ampla, como sugeriu Candido em relação à literatura?

Em segundo lugar: muitas vezes, até mesmo em casos ditos "incompressíveis" como a moradia, o bem em questão é oferecido em condições industriais extremamente precárias, ligadas aos projetos mais obsoletos da primeira modernização. Aqueles que se inserem nessa oferta com a melhor das intenções estão de fato propondo algo, ou apenas reproduzindo os moldes de uma época que já provou seu colapso com a demolição dos conjuntos habitacionais como ode Pruitt-Igoe, em St. Louis?

No Brasil, sobretudo a partir dos anos 60, muitos dos projetos modernistas de moradia, assumiram formas estereotipadas de edifícios laminados em série, alegadamente no intuito de fazer frente à demanda habitacional, com pouco ou nenhum tratamento de seus espaços livres externos, os quais, em qualquer assentamento (mais) humano se destinariam ao lazer, à recreação, ao esporte, à circulação e à convivência, entre outros. Também é oportuno lembrar dos assentamentos com edificações unifamiliares cuja paisagem remete mais a um melancólico e seriado conjunto de 'casas de pombo'; são assentamentos que, no tempo, ganharão puxadinhos e apropriações espontâneas, não raro por meio de muito ônus de tempo e energia, alterando livres e construídos , numa explícita demonstração de que habitar é mais do que ter realizado o sonho da casa própria e diz respeito mais a uma ideia de habitat - o habitar a cidade (e não apenas o habitar na cidade), onde o espaço livre público é uma parte fundamental. As lições de Pruitt-Igoe, aí estão para demonstrar, entre outros aspectos, que o direito à cidade inclui também o direito às áreas de lazer qualificadas, ruas e calçadas arborizadas, e bem mantidas.

A rigor, e isso é bastante curioso, o direito a esses bens 'compressíveis', quase nunca foi uma pauta importante da esquerda quando à frente da gestão pública no âmbito das políticas habitacionais, o que faz com que conjuntos em gestões progressistas tenham configurações similares aos realizados em outras administrações públicas mais conservadoras.

Inspirados na provocação feita por Antonio Candido, em sua reflexão sobre a pertinência dos direitos tidos como compressíveis e a partir dessas inquietações acima as quais têm encontrado ressonância, inclusive, em áreas periféricas urbanas, é que aqui se postula o que chamaremos de "direito à paisagem". 


\section{A questão da paisagem}

Muito embora no âmbito acadêmico, sobretudo a partir do século XIX, a questão da paisagem, em seu domínio epistemológico, tenha ganhado força com a contribuição de ciências como a Geografia, a Ecologia e mesmo a Filosofia (para a qual a paisagem é um problema, dado o seu caráter ontológico), ainda há um grande tabu acerca da sua inserção em pautas emergentes das políticas públicas, por se situar, justamente, no território dos direitos incompressíveis. Para que serve a paisagem, afinal?

Cabe aqui uma reflexão, ainda que sucinta, acerca da ideia de paisagem e sua polissemia. Conceitos são formulações da cultura em dado momento histórico. O memorável livro de Robert Lenoble "História da Ideia de Natureza" (1990) mostra que mesmo a noção de natureza nunca foi natural e sim uma construção, no tempo, movida por causas distintas e decorrentes (também) da relação do homem com o mundo. O mesmo vale para a ideia de paisagem que, para Sir Geoffrey Jellicoe em sua obra "The Landscape of Man" (1985), conforma-se a partir de variadas instâncias tais como as características ambientais de um lugar (relevo, hidrografia, vegetação, etc.), a sua história econômica e cultural, o pensar artístico em dado momento histórico, as correntes filosóficas da época e o conceito prevalente de natureza na esfera da cultura. Todas essas condições prévias têm, igualmente, sua materialização no campo da Arquitetura da Paisagem (ou Paisagismo), como síntese estética e socioambiental.

Embora a ideia de paisagem tenha existido sempre que alguém a tenha contemplado sem uma finalidade específica, os historiadores da paisagem, segundo Marc Besse "há tempos atribuem à carta na qual Petrarca faz o relato da sua ascensão ao monte Ventoux um valor inaugural”. Afirma Besse: “... Petrarca, decidindo escalar a montanha para simplesmente fruir da vista que pode ser desfrutada do seu cimo, teria sido o primeiro a encontrar a fórmula da experiência paisagística no sentido próprio do termo: a da contemplação desinteressada...”(BESSE,2006, p.1).Com efeito, essa parece ser ainda uma apreensão válida para as questões contemporâneas urbanas; como experiência estética (aesthesis), a paisagem se coloca no campo dos afetos (no sentido de afecção) e em oposição ao automatismo das cidades apressadas, capazes de anestesiar a percepção dos seus habitantes. 
A ideia do que seria a paisagem encontra-se fortemente atrelada à influência dos pintores paisagistas, que a celebram, principalmente a partir do Renascimento (com o recurso da perspectiva, entre outros), quando visões idílicas e pastorais se impregnam gradativamente ao conceito.

As obras dos pintores setecentistas Claude Lorrain e Nicolas Poussin, por sua vez, enlevam o imaginário do gentry inglês, em um contexto histórico de segunda revolução industrial, no qual as cidades enfumaçadas (sobretudo da Inglaterra) sugeriam a paisagem campestre como antídoto (figura 1). No limite, proprietários rurais solicitavam aos paisagistas e jardineiros que compusessem os jardins de suas propriedades de acordo com cenas pastorais consagradas nas pinturas. As virtudes morais do campo eram celebradas, nos séculos. XVIII e XVII inglês, em contraponto aos valores modernos e pragmáticos das cidades industriais com seus inúmeros malefícios à saúde da nova classe trabalhadora e da população em geral.

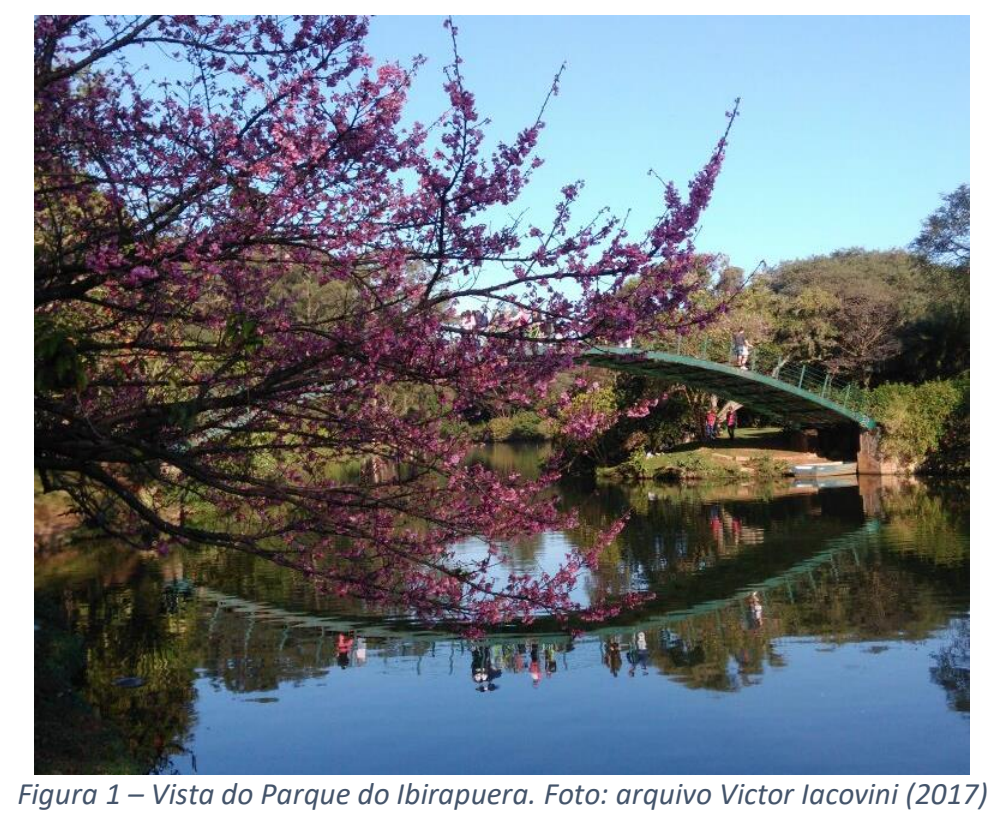

Essa mudança cultural teve grande influência na concepção de vários estilos do paisagismo inglês, como o denominado "the English Landscape Garden”, contribuindo fortemente para novas concepções de urbanismo, como o Movimento das cidadesjardins e já no século XX, para o Movimento Americano de Parques, entre vários outros. As visadas estéticas de inspiração campesina, nos dias atuais, parecem ainda influenciar o que se espera esteticamente de um parque público; cenas de matizes pastorais podem ser encontradas em parques do sec. XIX, como o Central Park em Nova York, o Birkenhead Park, na Inglaterra e o Campo de Santana (Praça da 
República), no Rio de Janeiro, e também nos parques do Sec. XX como o Ibirapuera, em São Paulo.

A rigor, é fácil observar como isso ficou cristalizado no imaginário popular urbano; frequentemente concepções de paisagem estão, ainda hoje, associadas à presença expressiva de elementos da natureza em ambientes, calmos, verdejantes com cenas de lagos tranquilos.

Entretanto, recentes estudos no âmbito da Fenomenologia, alçam a paisagem à outra categoria; Vera Pallamim, interpretando o filósofo Merleau-Ponty argumenta que “a paisagem é um lugar fenomênico, definido por nosso olhar, nossas tarefas, nosso mundo de implantação diante das coisas, como resultante da coexistência entre nós e o mundo". Nos termos de Merleau-Ponty, pode-se afirmar que perceber uma paisagem não significa recebê-la passivamente, é vive-la, recolhe-la, assimilá-la, reencontrar seu sentido, sabendo-se que o sentido do percebido não é constituído (idealizado por um sujeito pensante), mas sim nele instituído. (Pallamim et alli, 2014, p.25 e 26)

Abre-se assim, uma nova chave para a compreensão da importância da ideia de paisagem. Sendo a totalidade que se expressa, a partir do ponto em que é percebida, a paisagem 'acontece' em uma relação entre, pode-se arriscar, sujeito-sujeito; o mundo e o ser que mutuamente se afetam: "O homem procura a Terra, ele espera e chama por ela com todo seu ser. Antes mesmo de encontrá-la, ele vai ao seu encontro e a reconhece" (DARDEL, 1990, p.60).

Dessa forma, a paisagem se oferece, generosamente, à experiência estética da fruição desinteressada (para quem tem o tempo livre para experienciá-la), mas, também na chave política de uma leitura crítica de mundo, uma vez que as impressões do homem sobre a terra, nela estão grafadas, por vezes sob camadas que aguardam decodificação. Por definição de Éric Dardel, paisagem é a manifestação da mão humana sobre a Terra (BESSE, 2006).

Nesse sentido de afeto, a ideia de paisagem, transcende à acepção do belo à qual se encontra fortemente atrelada, ainda que possa incorporar tal noção (figura 2). Por outro lado, na chave da apreensão sensível do cotidiano urbano, a paisagem não é mais (apenas) o "que está lá", até onde a vista alcança, mas, o "aqui e agora" na experiência dos afetos cotidianos; é o corpo percebendo e se deixando afetar ("para o bem e para o mal") pelo espaço da cidade. 


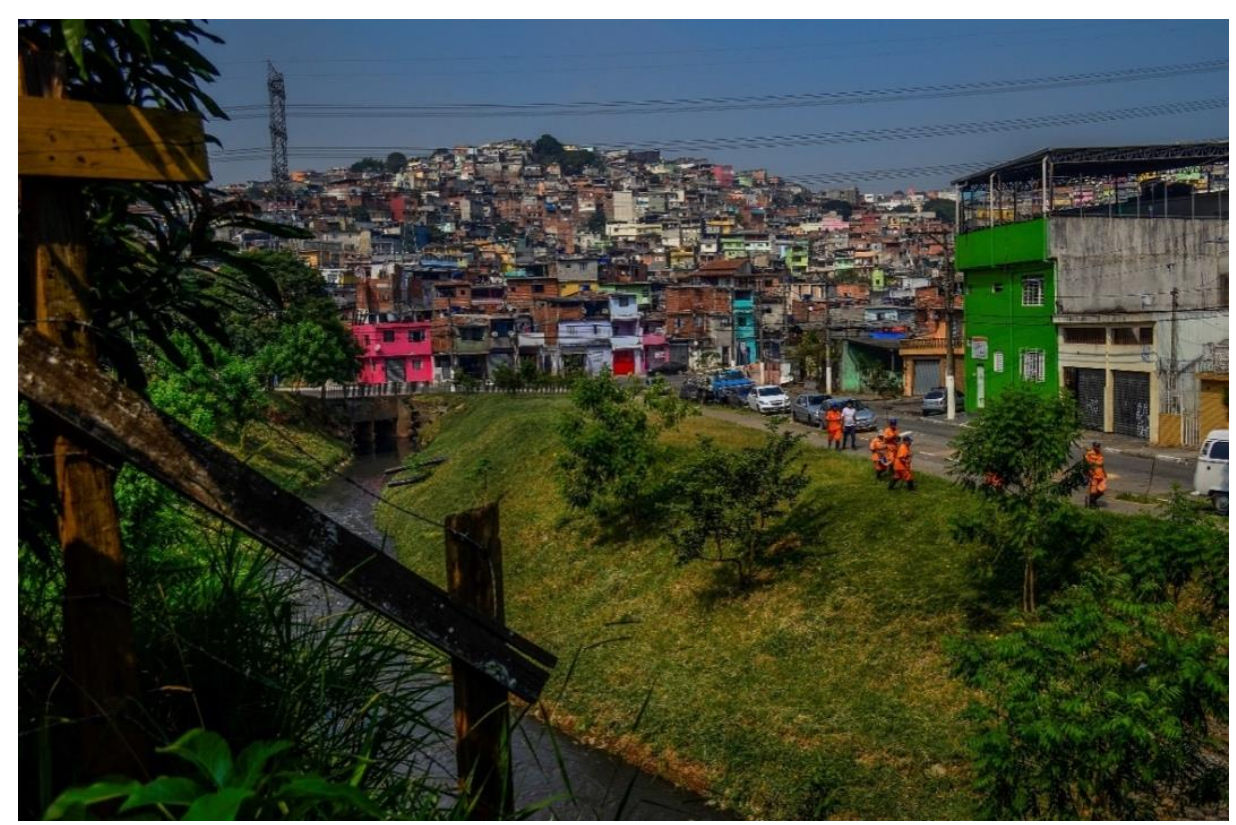

Figura 2 -Brasilândia, São Paulo. fonte: arquivo Juliana Freitas (2016)

Como observou Adriana Serrão, a paisagem é "não apenas visual, mas real, por isso, não em oposição à cidade” (Serrão, 2012, p.66). Assim compreendido, o conceito vai ao centro do debate sobre o direito à cidade, como parte inalienável deste e não como instância cosmética, ornamental. A própria International Union for Conservation of Nature, nos anais de sua conferência realizada em 2004, na Inglaterra, o reconhece:

A paisagem interessa a todos nós. Afeta nossa vida diária; influencia como nos sentimos sobre os locais onde vivemos, trabalhamos e relaxamos; é nosso habitat humano e nossa história viva, um complexo misto de elementos culturais; dá-nos o contexto da biodiversidade e seus reflexos no funcionamento dos sistemas de terra e água; tem a capacidade de nos inspirar e incitar; pode nos dar um senso de identidade, pertencimento e influenciar diretamente nossa qualidade de vida, promovendo o bem-estar junto às comunidades locais. (IUCN, 2004, p.1).

Em última instância, portanto, a paisagem é capaz de fazer a mediação da natureza com a dimensão, por assim dizer, humana. Assim pensou a filósofa Adriana Serrão, como que indo ao encontro das já mencionadas caracterizações de Antonio Candido a respeito da literatura. Disse ela:

Contrariando a oposição estrita entre cidade domínio dos espaços (em superfície e gestão ilimitada dos recursos), a paisagem, pensamento das ligações, resguarda valores da sensibilidade, do acolhimento e da não violência. Por ser categoria sintética de objetivo e subjetivo, cumpre função mediadora entre os elementos singulares e uma totalidade maior inacessível" (SERRAO, 2012, p.69). 
Assim, na medida em que media a aproximação da natureza à dimensão humana, a paisagem se manifesta também na resistência aos lugares sem identidade, bem como aos estilos arquitetônicos "internacionais" e seus esquemas lineares e módulos uniformizantes: "Paisagens são geradoras de espaços de liberdade que resistem a toda imitação, apelas elas "oferecem a abertura do horizonte a perder de vista, o silêncio pleno e a noite estrelada. Um lugar existencial, mas também utopia” (SERRAO, 2012, p.70).

O conceito, assim formulado, evoca os postulados de Candido sobre o caráter inalienável da literatura que, embora usualmente tida como um bem compressível, frequentemente entendido na chave da contemplação das belas letras, adquire, quando reivindicada, um significado maior. Assim, do mesmo modo que a arte escrita, a paisagem "humaniza porque faz viver", ligada que está à decodificação da experiência de outrem, à organização mental, ao tempo livre, ou mesmo à possibilidade do sonhar e da formulação utópica.

\section{O direito ao espaço do tempo livre}

A discussão sobre o direito ao tempo livre trata, na verdade, do direito à utilização do tempo em atividades autonomamente escolhidas. Essa escolha nos é cada vez mais rara: pressões sobre quanto e como despender nosso tempo de vida surgem por todos os lados, determinando quais atividades são válidas, e quais são "desperdício" de tempo. A medida dessa validade é determinada sempre mais pelo "retorno" desse investimento, em um processo de monetarização do tempo.

A mesma abstração que caracteriza o modo capitalista de produção se expande agora para todos os outros setores da sociedade e consolida uma lógica produtivista unitária. É assim que todas as atividades devem ser realizadas no mesmo tempo socialmente determinado, mesmo fora da esfera da produção. A pressão para a redução dos tempos dedicados a cada tarefa faz com que a atenção do indivíduo esteja sempre fragmentada, distribuída entre muitos afazeres que não lhe permitem autonomia, padronizando ritmos de vida numa rotina monótona, enervante, alienadora. Sobreviver a estas pressões exige a adoção de comportamentos repetitivos, quase inconscientes, que não permitem aquilo que distingue o ser humano: a consciência criadora. 
A assimilação da lógica de produção industrial pela sociedade tem seus reflexos nas formas de produzir e pensar a cidade, o mundo construído pelo e para o homem. A terra urbana como mercadoria orienta a conformação do espaço citadino de forma segregada e desigual. A adoção generalizada de um planejamento pragmático hierarquiza os investimentos entre necessidades básicas e secundárias (ou incompressíveis e compressíveis, para continuarmos com a terminologia de Candido).

Esta forma de produzir a cidade é mais fielmente traduzida nos princípios do pensamento urbano modernista. Tal modo de ver o mundo extrapola a racionalidade da produção industrial para o ordenamento da cidade e é fruto de um lento desenvolvimento de ideias - bem-intencionadas em sua maioria. Sua concretização nos permite compreender o raciocínio que a orienta: como produzir muito em pouco tempo e com os recursos possíveis?

O fortalecimento dessa linha de pensamento se dá no período pós-guerra, em que a demanda por atendimento exigia a produção em massa, abstraindo os cidadãos individuais em um somatório de demandas e carências homogêneas, unidade básica do planejamento denominada "usuário final” (Carvalho, 2011, p.47-48).

Assim a cidade se torna uma planta fabril, hierarquizada, setorizada, funcionalista - e em crise, denuncia Lefebvre já na década de 1960. Lefebvre explica que a separação brutal entre os conteúdos econômicos e históricos no capitalismo se reflete no ambiente urbano: na medida em que as escalas micro e macro se separam, aquilo que chamamos arquitetura se separa do que chamamos de urbanismo (Lefebvre, 2000).

Com o repetitivo substituindo a unicidade, o espaço passa a representar o triunfo do factual e do sofisticado sobre o espontâneo e o natural, o triunfo do produto sobre a produção e finalmente o triunfo dos gestos e atitudes repetitivas que transformam o espaço urbano em produtos homogêneos que podem ser vendidos ou comprados. A diferença entre os espaços passa a se dar pela quantidade de dinheiro empregada, reinando a quantificação e a repetição.

Ainda segundo Lefebvre, é justamente o abandono da Festa, ou seja, o uso dos recursos urbanos sem outra finalidade que o prazer, que origina a crise urbana (Lefebvre, 2001). É a sequência regrada de ações pré-determinadas a partir da abstração da individualidade em usuários padrões, que se estendem mesmo para o tempo (e espaços) da cidade. Assim, o espaço da cidade aliena o homem, tal como a rotina do 
trabalho, por não lhe permitir mais a ação autônoma e consciente, subsumindo-o numa sequência de espaços funcionalmente setorizados, pragmaticamente distribuídos e feios.

O planejamento modernista, a escola de pensamento urbano que assume a justificativa teórica do funcionalismo, já recebeu críticas suficientes para ser ainda oficialmente adotada. Entretanto, em muitas políticas públicas observa-se ainda um discurso similar: adotar racionalidades diversificadas e específicas exigiria um aprofundamento de análises que não se insere nos orçamentos e prazos exíguos - o benefício não valeria o custo. É por isso que se vê projetos de espaços públicos “de lazer" desenhados como se espaços abstratos fossem, com equipamentos distribuídos a intervalos geometricamente regulares: academias (padrão) para idosos, brinquedos (padrão) para os pequenos, quadras (padrão) poliesportivas para os jovens. A cidade abstrata pode ser árida para quem não é padrão (e alguém é?).

Mesmo os espaços que são alvos de projetos mais detalhados acabam vítimas de problemas similares. Angelo Serpa, em estudo em Paris e Salvador, demonstra como mesmo projetos paisagísticos preocupados com o lugar correm risco de reproduzir um novo estereótipo: o de adotar gostos e linguagens do que denomina 'as novas classes médias' como uniformes para toda a sociedade. (SERPA, 2008, p. 21-36).

A escolha não é aleatória: tais classes são destino final das atuais políticas públicas urbanas, que visam multiplicar o uso (o consumo, diríamos) do espaço urbano como estratégia de valorização imobiliária. Serpa define estas novas classes médias como posições socioeconômicas equivalentes, classificadas por um nível elevado de estudos, cujo lazer e consumo são os "motores" de complexas transformações urbanas. São para estes setores da sociedade que se destina o urbanismo da "cidade-espetáculo", como parte de uma política de fomento do consumo e do "lazer festivo", com privilégio de lugares 'visíveis' e gosto pelo 'grande espetáculo'. Tais espaços permanecem distantes para um público de perfil mais popular que habita as periferias metropolitanas (seja em Paris, seja em Salvador). São intervenções "cosméticas”, que mudam o espaço urbano para garantir que a cidade permaneça como está.

Aliás, na divisão de atribuições que caracteriza a sociedade mundializada atual, percebe-se que não é aos grupos sociais denominados "populares" que se destinam as cidades. No máximo, e aí podemos retornar a Lefebvre, estes ocupam os espaços das 
periferias $^{5}$, entre a impessoalidade dos projetos de habitação em massa e as variadas soluções autoconstruídas, nos limites da inadequação. A lógica do mercado de terras urbana lhes garante sua permanente situação de exclusão, pois à medida que as áreas recebem infraestruturas se tornam mais valorizadas, impelindo os excluídos do projeto a procurarem espaços mais baratos.

Especialmente no caso brasileiro, a cidade se expande sem um controle estatal, a fim de remediar danos, ao invés de preveni-los. Por isso, os investimentos públicos destinados a estes setores concentram-se principalmente no fornecimento (mesmo assim, insatisfatório frente à demanda) de serviços denominados básicos (moradia, infraestruturas de abastecimento e saneamento, equipamentos sociais). Nesse contexto, o discurso da racionalização de investimentos naquilo que se denomina básico (ou “incompressível”) é ainda mais sedutor. Apesar das boas intenções do discurso, o resultado pode ser resumido nas palavras de Davi (*):

Porque aqui nós temos: nós precisamos de um médico, tá aqui pertinho; nós precisamos de uma farmácia, tamo pertinho; nós precisamos de um mercado, tamo pertinho, né? Única coisa que nós não temos, é o lazer. É o lazer. Que pobre não tem lazer. Você sabe qual é o lazer do pobre? Não sabe, não? É o trabalho. O lazer do pobre é o trabalho, é o cabo da enxada, né? É carpir o quintal, é trabalhando em obra. Esse é o lazer do pobre. (Peabiru, 2017)

Por isso, demandas por aspectos aparentemente "compressíveis" são importantes na redescoberta da cidade como patrimônio dos seus cidadãos. Quando grupos de pessoas se mobilizam em prol de mais do que a sobrevivência, é a descoberta do humano em si uma das possibilidades mais fascinantes, e talvez a explicação da evolução de um processo como o Parque Taksim Gezi ou do Cais Estelita. Os movimentos de descoberta no cotidiano são em si oportunidades de resistência contra a abstração, em que pese a imposição sempre maior da rotina alienante e alienada. São verdadeiras ações políticas, no que rompem com a ordem vigente, criando novos espaços de participação verdadeira (Pallamin, 2015). Nas palavras de Pedro (*):

As pessoas não pode ir passear no fim de semana. Quer dizer, é tipo um presídio. Quer dizer que eles só quer o que? Eles só quer a força de trabalho do povo, não quer que o povo tenha um lazer, né? Como que o povo vai ocupar a mente só no serviço e não ter um lazer? Sem ter uma distração na mente, né? Então eu acho um absurdo isso que nós vivemos hoje, né? Eles querem voltar o tempo de antigamente, e

\footnotetext{
${ }^{5}$ Aqui, classificamos determinadas áreas como periféricas não a partir de uma distância geométrica das zonas centrais, mas sim da dificuldade de acesso a determinados bens e serviços (QUEIROGA, 2012)
} 
pode ver que ta voltando. Se o povo não reagir, se o povo não voltar, se o povo não por sua cabeça no lugar, não ter uma reivindicação, eles nunca vai sair da exploração, né? Então... Isso que eu acho comigo, isso daí. (Peabiru, 2017)

Apesar de a cotidianidade ser um espaço de repetição e pouca reflexão, existem brechas em que o comportamento automático é questionado, exigindo a atenção do indivíduo (Heller, 2008, p.34). Como já observamos, Antonio Candido enxergou na literatura um desses espaços. Assim, encontramos convergências entre as reivindicações dos mais diversos direitos humanos, não apenas no que diz respeito ao lazer, ao relaxamento ou à desalienação de um cotidiano automatizado, como também no que se refere à possibilidade de formular alternativas (utópicas ou não) ao presente. Foi a isso a que Agnes Heller se referiu, quando postulou que, quanto maior o grau de decisão autônoma, de consciência, maiores as possibilidades de desalienação do homem. Aí surgem as possibilidades de criatividade no cotidiano.

Essa criatividade individual pode ser quase uma tática de sobrevivência num ambiente hostil, tal como nos apresenta Michel de Certeau (1997), ao se referir às "formas microbianas de resistência" pelas quais os habitantes da cidade reconstituem no tempo os espaços dominados pelas estratégias estatais. São elas que, ao dissociar as micro-decisões da macroestrutura dominante, permitem aos usuários tornarem-se produtores autônomos, porém somente a partir de táticas "sem identidade legível, sem tomadas apreensíveis, sem transparências racionais" (CERTEAU, 1998, p.174), assim classificadas por distanciarem-se das narrativas oficiais inscritas no espaço.

Daí a importância do tempo livre e da busca por bens não-funcionais. São decisões de autonomia, que reforçam a consciência do humano de si mesmo como indivíduo autônomo. São oportunidades, no dizer de John Holloway (2013), de fissurar a espessa camada de inconsciência a que somos submetidas, na corrida sempre frenética do dia-a-dia. Se entendermos a paisagem como uma relação sujeito-sujeito, tal como dito anteriormente, de integração consciente entre um indivíduo e seu espaço de vida (Berleant, 1997, p.11), percebemos sua importância crucial na produção de uma cidade concreta, humanizadora e humanizada, ao invés da "insensata megalópole industrial", desconexa e temporânea (Assunto, 2011, p. 357).

Colocadas em abstrato, todas essas propostas podem parecer muito vagas. Contudo, nos interessa pensar como, do debate em torno da constituição de 1988 às manifestações de rua do século XXI, determinados bens tidos como "compressíveis" 
vêm se inserindo em uma luta ampla por uma vida mais humana. Essa outra vida, em que pese seu caráter não-imaginado, encontra na possibilidade da imaginação utópica justamente seu espaço possível de formulação, do que retornamos à necessidade dos mesmos bens supostamente compressíveis (como a paisagem, a literatura, o lazer) enquanto fatores indispensáveis no contraponto à unidimensionalidade do cotidiano automatizado em que vivemos. Trata-se de uma relação dialética que, aliás, tem as mais práticas consequências, inclusive não desvinculadas das questões mais tradicionais (reivindicação de proteções trabalhistas que permitam o tempo livre, por exemplo).

Além disso, gostaríamos de lembrar quão vagos são os próprios ideais hegemônicos, em seu caráter uniformizador. Estes, para se sustentar, precisam se tornar abstratos ao ponto de ignorar completamente a demanda das próprias populações que vêm se organizando em torno de exigências tratadas como supérfluas e não-estruturais, mas que, na verdade, apontam para as mais qualitativas das possibilidades.

Em suma, portanto, não é de nossa intenção reviver uma dicotomia bizantina entre a utilidade do inútil e o caráter mais palpável do necessário (seja em que forma ele se apresente). Ao contrário: gostaríamos de assinalar que esse tipo de debate já não possui o menor interesse, visto a absoluta imprescindibilidade do que as ruas vêm reivindicando e que- na mesma medida - vem se ignorando completamente na agenda pública.

\section{Conclusão}

Não parece coincidência que campos tão diversos quanto a paisagem e a literatura tenham sido conceituados de formas aproximáveis ao longo do século $\mathrm{XX}$. Como que indo ao encontro da caracterização de Candido sobre a incompressibilidade da arte escrita, Custódio afirma:

... mesmo desiguais devem, pelo princípio democrático, ter oportunidades iguais e acesso possível à paisagem, bem como oportunidades iguais de opinar e participar das modificações da paisagem, já que é de todos e tem função e representatividade para todos". (CUSTÓDIO, 2015, p.15)

No presente artigo, buscamos postular que essa proteção do "direito à paisagem", enquanto possibilidade de se disponibilizar à experiência estética da fruição desinteressada, vincula-se ao "direito $d a$ paisagem", entendida agora como acesso à 
leitura crítica de mundo, capaz de mobilizar os indivíduos em prol de uma vida mais humanizada. Como demonstramos, foi esse - em grande medida - o sentido do direito à literatura em Candido.

Tais questões, no grande espectro dos direitos humanos, encontram paralelo com outras pautas que lentamente vêm solicitando seu lugar na agenda oficial dos governos, a partir de movimentos surgidos das ruas nos últimos anos. Objetivamos, portanto, assinalar que tais reivindicações são fundamentais à possibilidade de construção de uma sociedade diversa - razão pela qual não podem jamais ser ignoradas. Em outras palavras, para além de qualificar reivindicações mais imediatas, "incompressíveis" (como a moradia, o fim da violência policial), contribuem para uma nova perspectiva de sociedade ultimamente ausente das administrações à direita ou à esquerda.

\section{Bibliografia}

ASSUNTO, R. A paisagem e a estética. In SERRÃO, A. V. (coord). Filosofia da Paisagem. Uma antologia. Lisboa, Centro de Filosofia da Universidade de Lisboa, 2011.

BERLEANT, A. Living in the Landscape. Toward an aesthetics of environment. University Press of Kansas, 1997

BERQUE, Augustin. L'écomène, mesure terrestre de l'homme, mesure humaine de la Terre: pour une problématique du monde ambient. L' Espace géographique, 4, p.304. 1993. 1994.

Cinq propositions pour une théorie du paysage. Seyssel: Champ Vallon,

EAGLETON, Terry. Literary theory: an introduction. Minneapolis University Press, 1996.

CANDIDO, Antonio. A importância da leitura. Em: a literatura e a formação da consciência. São Paulo: Cadernos de Estudos da Escola Nacional Florestan Fernandes, número 2, 2007.

Antonio. Literatura e Subdesenvolvimento. Em: A Educação pela Noite. Rio de Janeiro: Ouro sobre Azul, 2011.

CARVAlHO, M.C.B. e NETTO, J. P. Cotidiano: conhecimento e crítica. São Paulo: Cortez, 2011.

CERTEAU, M. de. A invenção do Cotidiano. São Paulo: Ed. Vozes, 1998

CUSTÓDIO, Maraluce. Paisagem: subsídios para a construção de um conceito democrático no direito brasileiro. $3^{\circ}$ Colóquio Ibero-americano. Belo Horizonte, 2014. Disponível em: http://www.forumpatrimonio.com.br/paisagem2014/trabalho/14/paisagem-subsidios- 
para-a-construcao-de-um-conceito-democratico-no-direito-brasileiro. Acessado: 25-jul2017.

DARDEL. Eric. L'homme et la terre. Nature de la réalité géographique. Paris: Editions CTHS, 1990.

FISCHER, Ernest. A necessidade da arte. Tradução: Leandro Konder. Rio de Janeiro: Zahar, 1977.

HAN, Byung-Chul. A sociedade do cansaço. Tradução: Enio Paulo Gianchini. Petrópolis: Vozes, 2015.

HELlER, A. O cotidiano e a História. Tradução de Carlos Nelson Coutinho e Leandro Konder. São Paulo: Paz e Terra, 2008

HOLLOWAY, John. Fissurar o capitalismo. Traduzido por Daniel Cunha. São Paulo: Publisher Brasil, 2013.

IUCN. Future landscapes: working with the principles of the European Landscapes Convention. Conference on 'Future landscapes - Working with the Principles of the European Landscape Convention' which was held in oxford 7-9, May 2004, ICOMOSUK, and IUCN UK Committees Disponível em http://pt.scribd.com/doc/4243088/Future-Landscapes-2004.

JELLICOE, G. The Landscape of man. Ed. Thames and Hudson. London: 1985

LEFEBVRE, H. A produção do espaço. Trad. Doralice Barros Pereira e Sérgio Martins (do original: La production de l'espace. 4e éd. Paris: Éditions Anthropos, 2000)

O direito à cidade. São Paulo: Moraes Ltda. Tradução Rubens Eduardo Frias. São Paulo: Centauro, 2001.

LENOBLE, R. História da ideia de natureza. Rio de janeiro. Editora 70: 1990

PALLAMIN, V. Arte, Cultura e Cidade. Aspectos estético-políticos contemporâneos. Editora Annablume. São Paulo: 2015.

PALLAMIN, V. (pesquisadora responsável), ARANHA, C., BARTALINI, V., Lima, C. Fenomenologia e Paisagem: espaços de transitividade em intervenções associadas ao paisagismo e arte contemporâneos. Pesquisa realizada com apoio da FAPESP-20122014 - proc. $\mathrm{n}^{\mathrm{o}} 01735-1$

PEABIRU. É o que eu penso e é o que eu vejo - transcrição de entrevistas realizadas para o documentário de curta metragem. São Paulo: Mímeo, 2017

QUEIROGA, Eugenio. Dimensões Públicas do Espaço Contemporâneo: Resistências e Transformações em Territórios, Paisagens e Lugares Urbanos Brasileiros. Tese (Livre Docência em Arquitetura e Urbanismo) - FAUUSP. São Paulo, 2012.

SERPA, A. Espaço Público na Cidade Contemporânea. Ed. Contexto. São Paulo, 2007 


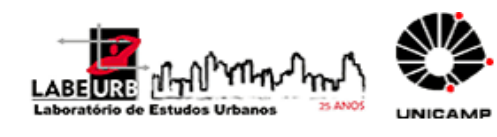

\section{Para citar essa obra:}

LIMA, Catharina P. C. S.; ALBUQUERQUE; Elaine M. de; LIMA, Gabriel C. dos Santos, WEHMANN, Hulda Erna. O direito ao (in) compressível: arte, cidade, paisagem e transformação social. In: RUA [online]. $n^{\circ}$. 23. Volume 2, p. 291 - 309 - e-ISSN 2179-9911 - Novembro/2017. Consultada no Portal Labeurb - Revista do Laboratório de Estudos Urbanos do Núcleo de Desenvolvimento da Criatividade.

http://www.labeurb.unicamp.br/rua/

Capa: Figura 3 -Brasilândia, São Paulo. fonte: arquivo Juliana Freitas (2016)

Laboratório de Estudos Urbanos - LABEURB

Núcleo de Desenvolvimento da Criatividade - NUDECRI

Universidade Estadual de Campinas - UNICAMP

http://www.labeurb.unicamp.br/

Endereço:

LABEURB - LABORATÓRIO DE ESTUDOS URBANOS

UNICAMP/COCEN / NUDECRI

CAIXA POSTAL 6166

Campinas/SP - Brasil

CEP 13083-892

Fone/ Fax: (19) 3521-7900

Contato: http://www.labeurb.unicamp.br/contato 